\title{
Resistance to Ritual Practice: Exploring Perceptions of Others \\ Research Paper
}

\begin{abstract}
Purpose This paper contributes to the special issue theme by exploring the perceptions of anti-consumption and resistant practices of adolescents by their peer group in the context of high school prom attendance. Originality Possible causes for avoiding consumption have been previously considered however, as yet unexplored are how those who do not consume are perceived by their peers and how this manifests itself in relation to group affiliation, attendees' perception of 'self' and social norms. Methodology/Sampling This paper employs a mixed methods approach involving 12 in-depth interviews with those who had attended a high school prom in the last three years and open questions on a survey to adolescents. Findings Four main perceptions of non-attendance were identified: non-choice, risk aversion, passive disengagement and intentional disengagement. Perceptions of anticonsumption and resistance will have social implications for the non-attendee/s but the extent to which non-attendance is viewed negatively will also be moderated by existing social status of the non-attendee/s.
\end{abstract}

Key Words: Adolescents, Prom, Resistance, Peer Affiliation and Perception

\section{Introduction}

This paper explores perceptions of anti-consumption and the resistant practices of adolescents by their peer group in the context of high school prom attendance. If, as suggested by Cherrier, Black and Lee (this issue) anti-consumption focuses on 
specific acts against consumption which relate to a person's self identity project, this paper contributes to this special issue theme by considering the perception of anticonsumers by others in their peer group. As perceptions of others can affect the degree to which adolescents integrate and given that self esteem is influenced by social comparisons and reflected appraisals (McElhaney et al, 2008; Rosenberg and Perlin, 1978) it would be useful to explore the perception of others in the context of both anti-consumption and resistant practice.

The notion of the school prom historically has been to signal the transition of youths to adulthood and Duffy (2007) suggests that although less than a decade ago 'proms' were an exclusive part of American life in the past decade it has become a rite of passage for adolescents living in the UK. As yet unexplored however, are the implications of non-attendance for those anti-consumers or those resisting this ritual event. How are those who do not attend the high school prom perceived by those attending the high school prom and how does this manifest itself in relation to peer group affiliation, attendees' perception of 'self' and social norms?

\section{Individual and Group Resistance}

Consuming (and conversely non or anti consumption) is a complex social phenomenon especially with regard to adolescents (Benn, 2004) not least because of their need to express individuality as well as blend in with their social group/s (Pickett et al, 2002). Their notion of self has to be developed and continuously restructured with regard to their changing experiences and environments (Giddens, 1991) and the degree to which they engage in and with (anti) social behaviour will in part be related to the ability of the individual or group to resist or comply with expectations and social norms (Oetting et al, 1998). Kozinets and Handleman (1998) indicate that anti- 
consumers choose to define themselves in opposition to the dominant consumer culture and teenagers are known to engage in imaginative acts of defiance (Russell and Tyler, 2005). Cherrier (2009), however, notes that resistance to consumption is not necessarily easy to assume as it can be emotionally (and financially) costly. Best (2000: 28) suggests that social control operates in the context of high school prom attendance and that 'the fear of having missed the prom is harnessed as a mechanism to gain students consent to this event and the material and ideological conditions it secures'. Not attending this ritual could be 'expensive' with regard to the development and maintenance of peer relationships during this liminal phase of transition. There could also be implications for adolescents not taking this opportunity to adopt, cultivate or reinforce a symbolic self.

\section{Peer Orientation and Resistance}

The extent to which individuals comply with the social expectations of attending the prom or their degree of subversion may depend on how important it is for them to be part of a social group to alleviate isolation (Pickett et al, 2002). For example, peeroriented adolescents who have a high involvement with their contemporaries have been found to have a negative self-concept, engage to a greater degree with anti-social behaviours (Billy and Udry, 1985; Kandel, 1996) and have a lower degree of wellbeing or self-esteem (Kandel and Davies, 1982; Conger et al, 1992). As consumer decisions are regularly made to enhance or protect self esteem (Banister and Hogg, 2004) although an individual might want to attend the high school prom the dominant culture appropriating this ritual event may be less influential than an adolescent's social group. That is, if the friendship group to which the adolescent belongs want to resist this practice, the individual may comply (See Abrams and Hogg, 1990). Interestingly, from a consumption perspective, children with low self-esteem are more 
likely to be susceptible to peer-group influence (Achenreiner, 1997) even though this may affect the perception of their behaviour by others.

Individual and even group resistant alternatives, particularly during adolescence, may be difficult to achieve. Some adolescents engaging in anti-consumption practices may be creative and rebellious in their behaviour but for others agency is overwhelmed and duped by producers (Kozinets et al, 2004). As the producers of the prom are often the organising committee made up of adolescent peers typically nominated to facilitate the end of school celebration, rejection though non-attendance may simply reinforce that those who do not attend are simply the homogenous 'out group' members (Banister and Hogg, 2004) as opposed to 'heroic individuals who elect whether they want to be part of the system' (Weber, 1948). Although agency implies that adolescents have the freedom to create, change and influence events, there are a number of factors affecting resistance. Adolescent's locus of control within a peer group and previous experience of resistance as well as cultural boundaries impact on the ability of the individual or social group to challenge referent group behaviour (Wasserman and Faust, 1994).

\section{Non Attendance (Anti-Consumption) of the High School Prom}

Early research on 'failure to consume' illustrates the difference between non-choice and anti-choice (Hogg, 1998). In the context of the high school prom, those who could not afford to go to the prom (e.g. those without the financial resource), those with no high school prom event and those who cannot access the prom (e.g. location makes the journey to the prom prohibitive) would have no choice as to whether they could go to the prom. Potential anti-consumption or resistance to prom attendance would come from those who had the resource, availability and access to a high school 
prom. This notion has been further developed by Cherrier et al (this issue) as resistance can be expressed through anti-consumption although anti-consumption does not necessarily contain an element of opposition. That is, resistance is relatively straightforward to recognise as it often takes the form of (active) boycotting (See for example Sen et al, 2001) where anti-consumption can be practised to develop identity projects or to fulfil elements of individual life without opposing an antagonist. This type of behaviour could be seen as more passive and perhaps more difficult to identify (Cf Hogg et al, 2009).

\section{Reasons for Anti-Consumption}

Hogg (1998) also details different degrees of anti-choice or anti-consumption (aversion, avoidance and abandonment). Aversion as an affective aspect of attitude (e.g. dislike, disgust, revulsion) will tend to precede avoidance or abandonment as it is likely to motivate the behavioural responses of avoidance or abandonment; in some cases to protect self esteem (Hogg et al, 2009). Further to this, Lee and Conroy (2005) and Lee et al (2009) have established three possible causes for avoiding consumption. Previous bad experience (s) may influence future consumption (experiential avoidance), disassociation with particular brands, products or services may be a motive for rejection (identity avoidance) and religious or cultural reasons may be a reason for refusal to consume. Piacentini and Banister (2009) considered the antecedents of anti-consumption within their framework of (anti) alcohol consumption and their study supported the findings of Lee and Conroy (2005) and Lee et al (2009) in a social marketing and excessive use context. As such the reasons for avoiding consumption appear to be somewhat appreciated. 


\section{This Study}

Attendance of the high school prom can afford the opportunity to develop a symbolic self (Tinson and Nuttall, 2010) but the extent to which adolescents use non-attendance of the prom to form or maintain an identity position (See for example Abrams and Hogg, 1990) has been somewhat under-researched. What is also less well known, as suggested by Piacentini and Banister (2009), is the perception of anti-consumers by others in their peer group.

It is well established that the concept of the 'self' is formed as a reflection of the responses and evaluations of others and that awareness of the perceptions of others is an indicator of social competence (Cooley, 1902; Campbell and Fehr, 1990). As such, although the reasons for anti-consumption may be increasingly well understood, the perceptions and, as a consequence, the implications of anti-consumption have yet to fully explored. Indeed, are there differing perceptions of those who resist consumption, comparatively with those who practice anti-consumption to develop their identity projects? Close and Zinkhan (2009) suggested that consumers may avoid, minimise or adapt consumption traditions (e.g. Christmas) but few, if any, studies have examined the rejection of a 'rite of passage' ritual and the implications this has for those who do embrace the tradition.

The purpose of this study was to: firstly to establish the way in which the nonattendees are perceived by those who attend the high school prom and secondly to explore the way in which non-attendance influences the attendees' perception of their 'self' and their own experience. Consequently, the following objectives for the study were set: 
- To consider if there is a perceived difference between anti-choice and resistance with regard to the prom and to investigate if and how this influences perception of non-attendance

- To explore the implications of anti-consumption (non-attendance) of the high school prom for the attendees perception of 'self' and to examine possible subsequent social or peer related implications for non-attendees

This research employs a mixed method approach as described by Johnson \& Onwuegbuzie (2004). Initially twelve interviews were organized with young adults (18-20 years of age) who had already attended a high school prom (See Table I). They were asked to consider their own high school prom experience (preparation, event and post evaluation) and to comment on who had not attended their prom and why they thought (or knew) this to be the case. In this way the data could be used to establish what happened at this ritual event as well as assist with the questionnaire design.

\section{Take in Table I}

Secondly data regarding perceptions of anti-consumption of the prom were also generated using open questions on a survey about a forthcoming prom $(n=81)$ (See Table II). Of a possible 178 pupils, 132 intended to go to the prom and 86 pupils completed questionnaires. Five of the questionnaires were incomplete and considered unusable. The open questions employed a projective (and more ethical) technique in order that attendees would not feel obliged to be specific about actual individuals in their year group as the prom was a current event (See Appendix 1). Permission for the research to be conducted was sought and given from the Head Teacher and by the 
adolescents involved in the project. The questionnaires were distributed by 3 adolescent girls who were pupils at the school 10 days before the high school prom was to take place in central Scotland.

For the analysis of the data an interpretive analytic stance was adopted and themes in the responses of adolescents were explored using the constant comparative method described by Glaser and Strauss (1967) and analytic induction (Bryman and Burgess, 1994). Each interview was examined to gain a holistic understanding of the respondent noting themes in the margin as they emerged (See Thompson and Hirschman, 1995). The data generated by the open questions was also indexed and patterns within the responses sought. All the themes were reviewed through iterations of comparison and re-reading. As a consequence of the relationship between emerging insights and prior assumptions, interpretations were developed (Spiggle, 1994).

\section{Take in Table II}

\section{Findings}

In order to consider if there was a difference between the perceptions of non-choice and anti-choice with regard to the prom it was important to establish why the attendees thought their peers did not attend. When analysing the data of the attendees from both the interviews and the questionnaire responses, four main perceptions of non-attendance emerged from an iteration process which "permitted the development of provisional categories, constructs, and conceptual connections for subsequent exploration" (Spiggle, 1994: 495). A discussion on the perceptions of the four types of non-attendees that were identified follows. 


\section{Non Consumption}

It was recognised by the attendees that there were those who simply could not afford to be present at the event and lack of resource, availability and access can explain non-choice (See Hogg, 1998). Interesting to note however was the perception that those who had 'no choice' were in a small minority.

\section{Risk Averse}

Many attendees noted that non-attendance of this event could be a self confidence related issue and that anti-consumption of the high school prom allowed these nonattendees not to have to put themselves in an uncomfortable position. Hogg et al (2009) note that anti-consumption-as-rejection is motivated by preserving self esteem and the perception of attendees, with regard to the anti-consumption of the prom, supports this assertion. Interestingly attendees feel sympathy for these non-attendees as they appear to understand their reasons for non-attendance.

Where non attendance of the event is outside the control of the non-attendee or where it reflects a perceived negative self perception, the attendees appear to be either neutral towards these non-attendees or have feelings of guilt and/or empathy towards them. The social implications of non-attendance in this context then is likely to be minimal for those with perceived non-choice or risk aversion as they will be either 'excused' their non-attendance and/or will maintain their current social position (possibly as 'out-group' members - however unappealing that social position may be) (Wasserman \& Faust, 1994). Although low self esteem has been linked with greater susceptibility to peer pressure (Achenreiner, 1997) it may be that non-attendees perceive themselves as not meeting the social expectations of the 'in-group' and that 
non-attendance is their only option. This needs greater exploration with non-attendees themselves.

\section{Passive Disengagement}

However non-attendees who were considered to passively disengage from the high school prom appeared to be a much maligned group and were portrayed as 'lazy', 'unwilling to socialise' or as 'people who are not willing to make an effort to join in and experience the night'. This group of non-attendees were not conforming to the social norms of the peer group as a whole. Possibly the attendees questioned their own motives for attending in respect of this resistance and it may also be that this type of non attendance reflects to a greater extent on the attendees' perception of their 'self' (and their need or reasons for conforming to the social or peer group norms) (Oetting et al, 1998). Adolescents who passively disengaged were seen to be resisting against the 'prom' practice and, as a consequence, those engaging with the event. The antagonists were the peers of those resisting the prom as well as, perhaps, the culture of consumption (although further research will be needed to explore this).

Although anti-consumption on the part of the passively disengaged non-attendees, as described by the attendees, appeared to represent dislike as opposed to disgust (Hogg et al, 2009) and as such the resistance towards the prom from the anti-consumers appeared to be weak, their behaviour seemed to generate a greater degree of negative feeling amongst the attendees towards the non-attendees. This would appear to potentially have greater implications for peer group integration as explored by Oetting et al. (1998) in relation to bonds (inclusion and exclusion) and influence within groups. That is, resistance would appear to generate greater ill-feeling than anti- 
consumption illustrating that, perceptions of anti-consumption and resistance differ with potential for conflict and (temporary) social exclusion as a consequence of the latter.

\section{Intentional Disengagement}

The interpretation of the data suggested that this type of non-attendance is often perceived by attendees as reinforcing an identity position (Abrams \& Hogg, 1990). Non-attendees who intentionally disengage are described as 'people who want to make a statement by not going' or 'people who think they are too cool for it [the prom]'. Whilst this type of behaviour is not as overt as boycotting (Sen et al, 2001) non-attendance of the high school prom is being used to strengthen and/or construct a 'self' that others in the peer group will recognise. This behaviour appears to illustrate the greatest degree of public resistance. Intentional disengagement can be akin to rejection and is relevant in the context of the location of the individual in the social network (Wasserman and Faust, 1994). As with those who passively disengage, there are elements of resistance against the peer group (antagonists) who are engaging with the event although aspects of this behaviour could also be akin to anti-consumption to fulfil elements of their own lives.

Although this non-attendee type of behaviour appears to generate ill-feeling about anti-consumption from the attendees there were exceptions to this (e.g. acceptance of non-attendance in the cases of 'moshers', a sub-culture to which some of the nonattendees belonged). Indeed there appeared to be less potential for negative consequences from non-attendance when those attending understood why the practice 
was being rejected. To that end, understanding the reasons for anti-consumption or resistance can affect perceptions of such behaviour.

\section{Discussion}

The strength of the adolescent's existing social position may affect the way in which s/he wants to be perceived (and as such s/he may suggest a specific reason for nonattendance). Wasserman and Faust 1994 and Ennett and Bauman (1996) illustrate that the position of the adolescent in their friendship group will determine the extent to which they are perceived in the social network. That is if an adolescent has a strong social position within their peer group the reason for non-attendance will have less of an impact on his/her social position. If, however, the social position is weak (or 'isolated' as described by Ennett and Bauman) the adolescent may have to be more careful when positing a reason for non-attendance in order to be positioned favourably (or to minimise negative views). In this case anti-consumption or anti-consumption as resistance allows choice for the individual in terms of mediating an identity position relative to the perception of consumers.

What is clear here is that there is evidence of anti-consumption as resistance as well as anti-consumption and whilst both may allow the development of identity projects (as to be expected during adolescence) the perceptions of such behaviour can influence social inclusion and attendees' own perceptions of self.

Perceptions of resistance to attending the high school prom vary, and that although some reasons for non-attendance or resistance appear to be 'acceptable' others challenge the social norms and could affect both group inclusion and attendees' 
perception of their own motivations. Further to this, whilst these findings suggest that there are four different types of non-attendees (as perceived by the attendees) it is possible that the perception of the non-attendees' behaviour is at risk of being distorted or misunderstood. That is, non-attendees here have been discussed as independent groups but as the majority of attendees suggested multiple reasons as to why they considered their peers not to have attended the prom this needs further exploration.

The need for further research in this area is supported by existing work on distortion or misunderstanding. Bernieri et al (1996) in their lens model analysis, consider the ways in which rapport is built between individuals and the implications this has for perceiving (accurately) the behaviour of others. Their findings indicate that social perception accuracy is higher in a co-operative context (See also: Bernieri et al, 1994). This suggests that if the attendees had better rapport (e.g. were close friends) with the non-attendees their perception of the non-attendance would be more accurate. Additionally, studies of organizational disidentification illustrate that individuals who disidentify with an organization tend to have limited personal experience with the organization and as a consequence hold stereotypical views about its members and possess narrow and simplified information regarding the organization (See Elsbach and Bhattacharya, 2001). Therefore it may be plausible to assume, that attendees' beliefs about the reasons for non-attendance may be more stereotypical and less reflective of the individual's true reasons for non-attendance. Non-attendees may have more than one reason for not consuming the prom although this needs further exploration with the non-attendees themselves. 


\section{Conclusions and Implications for Further Research}

The high school prom was used here as a lens through which to explore perceptions of anti-consumption and resistance to this ritual event and to consider the possible implications anti-consumption may have for adolescents and their peer group/s affiliation. The initial indications from this exploratory research suggest that both perceptions of anti-consumption and resistance and the degree of significance of nonattendance vary for those attending the high school prom. It has also been suggested here that the attendees' perception of non-attendance may be at risk of being be distorted or misunderstood. That is, the attendees can perceive one motive for nonattendance but that anti-consumption may occur for quite a different reason. This will affect the way in which the individual is able to mediate their own identity project as the concept of the self is a reflection of the responses and evaluations of others (Cooley, 1902; Campbell and Fehr, 1990).

The extent to which non-attendance will be viewed negatively will also be moderated by existing social status. The attendees perception of 'self' also appeared to be impinged upon by non-attendance of the high school prom (particularly in the cases of passive and intentional disengagement) and this was particularly apparent when the attendee considered the event to be unique or special. This resistance, as opposed to the anti-consumption of such an event, generated negative feelings in a way anticonsumption did not. This could be because the antagonists were the peer group (as well as the cultural or ritual practice and associated consumption behaviour).

It is obvious that the next phase of research will have to consider the views of the non-attendees; establishing reasons for and the implications of non-attendance and if 
and/or how anti-consumption or resistant practices were related to peer group assimilation or individual desire for differentiation. Non-attendees social relationships will be investigated specifically with regard to Social Identity Theory (See Abrams and Hogg, 1990) and the social identity of their friendship group/s. The concept of distortion (taking into account the views of the attendees) will also be examined as will notions of conforming to peer group practice to alleviate isolation and the consequences this has for adopting, cultivating or reinforcing a symbolic self. Distinguishing between the perceptions of resistance and anti-consumption as a way of mediating an identity position will also be further explored.

\section{References}

Abrams, D. and Hogg, M.A. (Eds) (1990), Social Identity Theory: Constructive and Critical Advances, Harvester Wheatsheaf, New York, NY.

Achenreiner, G. B. (1997), "Materialistic values and susceptibility to influenced in children", Advances in Consumer Research, Vol. 24, pp.82-88.

Banister, E. and Hogg, M. (2004), "Negative symbolic consumption and consumers' drive for self esteem: The case of the fashion industry", European Journal of Marketing, Vol. 38 No.7, pp. 850-868.

Benn, J. (2004), "Consumer education between 'consumership' and citizenship: experiences from studies of young people", International Journal of Consumer Studies, Vol.28 No.2, pp.108-116.

Billy, J.O. and Urdy, J.R. (1985), "Patterns of Adolescent Friendship and Effects on Sexual Behaviour", Social Psychology Quarterly, Vol.48, pp.27-41.

Bernieri, F. J., Zuckerman, M., Koestner, R. and Rosenthal R. (1994), "Measuring Person Perception Accuracy: Another Look at Self-Other Agreement", Personality and Social Psychology Bulletin, Vol.20 No. 4, pp.367-378.

Bernieri, F. J., Gillis, J., Davis, J and Grahe, J.E. (1996) "Dyad Rapport and the Accuracy of Its Judgement Across Situations: A Lens Model Analysis", Journal of Personality and Social Psychology, Vol.71 No. 1, pp.110-129.

Best, A. L. (2000), Prom Night: Youth, Schools and Popular Culture, Routledge/Farmer, New York, NY.

Bryman, A. and Burgess, R.G. (1994), Analyzing Qualitative Data, Routledge, London, UK.

Campbell, J.D. and Fehr, B. (1990), "Self-esteem and perceptions of conveyed impressions: Is negative affectivity associated with greater realism?", Journal of Personality and Social Psychology, Vol 58 No.1, pp.122-133.

Cherrier, H. (2009), "Anti-consumption discourses and consumer-resistant identities", Journal of Business Research, Vol.62 No.2, pp.181-190.

Close, A. and Zinkhan, G. (2009), "Market Resistance and Valentine's Day events", Journal of Business Research, Vol.62 No.2, pp.200-207. 
Conger, R.D., Conger, K., Elder, G., Lorenz, F., Simon, R. and Witbeck, L. (1992), "A family process model of economic hardship and adjustment of early adolescent boys", Child Development, Vol.63, pp.526-541.

Cooley, C.H. (1964) [1902], Human Nature and Social Order, Schocken Books, New York, NY.

Duffy, M. (2007), "Fizz, frocks and limos: get ready for the ultimate party", The Herald, 8 September, pp. 15.

Elsbach, K.D. and Bhattacharya, C.B. (2001) "Defining Who You Are By What You Not: Organizational Disidentification and the National Rifle Association", Organization Science, Vol. 12 No.4, pp.393-413

Ennett, S. T. and Bauman, K.E. (1996), "Adolescent Social Networks", Journal of Adolescent Research, Vol.11 No.2, pp.194-215.

Giddens, A. (1991), Modernity and Self Identity: Self and Society in the Late Modern Age, Polity Press, Cambridge, UK.

Glaser, B and Strauss, A. (1967), The Discovery of Grounded Theory: Strategies for Qualitative Research, Aldine, Chicago, IL.

Hogg, M. K. (1998), "Anti-constellations: exploring the impact of negation on consumption", Journal of Marketing Management, Vol.14 No.1, pp.133-158.

Hogg, M. K., Banister, E.N. and Stephenson, C.A. (2009), "Mapping symbolic (anti) consumption”, Journal of Business Research, Vol.62 No.2, pp. 148-159.

Johnson, R.B. and Onwuegbuzie, A.J. (2004), "Mixed Methods Research: A Research Paradigm Whose Time Has Come", Educational Researcher, Vol.33 No. 7, pp.14-26. Kandel, D.B. and Davies, M. (1982), "Epidemiology of depressive moods in adolescence. An empirical study", Archives of General Psychiatry, Vol.39, pp.12051212.

Kandel, D.B. (1996), "The Parental and Peer Context of Adolescent Deviance: An Algebra of Interpersonal Influences", Journal of Drug Issues, Vol.26, pp.298-315.

Kozinets R. and Handleman J. (1998), "Ensouling consumption: a netnographic exploration of the meaning of boycotting behaviour", Advances in Consumer Research, Vol.25, pp. 475-480.

Kozinets, R., Sherry, J.F., Storm, D., Nuttavuthist, K. and Deberry-Spence, B. (2004), "Ludic Agency and Retail Spectacle", Journal of Consumer Research, Vol.31 No.3, pp.658-672.

Lee, M.S.W. and Conroy, D. (2005), "Brand Avoidance: the brand as a market-based liability", in $34^{\text {th }}$ European Marketing Academy Conference Proceedings, Milan, Italy, 27th May 2005.

Lee, M. S.W., Motion, J. and Conroy, D. (2009), "Anti-consumption and brand avoidance", Journal of Business Research, Vol.62 No.2, pp169-180.

McElhaney, K.B., Antonishak, J. and Allen, J.P. (2008), “"'They Like Me, They Like Me Not": Popularity and Adolescents Perceptions of Acceptance Predicting Social Functioning Over Time", Child Development, Vol.79 No.3, pp.720-731.

Oetting, E.R., Deffenbacher, J.L. and Donnermeyer, J.F. (1998), "Primary Socialization Theory: The Role played by personal trait in the etiology of drug use and deviance", Substance Use and Misuse, Vol.33, pp1337-1366.

Piacentini, M. G. and Banister, E.N. (2009), "Managing anti-consumption in an excessive drinking culture", Journal of Business Research, Vol. 62 No.2, pp. 279-288. Pickett, C.L., Silver, M.D. and Brewer M.B. (2002), "The Impact of Assimilation and Differentiation Needs on Perceived Group Importance and Judgments of Ingroup Size", Personality and Social Psychology Bulletin, Vol. 28 No.4 pp.546-558. 
Rosenberg, M. and Pearlin, L.I. (1978), "Social Class and Self-Esteem Among Adults and Children", The American Journal of Sociology, Vol. 84 No.1, pp.53-77.

Russell, R. and Tyler M. (2005), "Branding and Bricolage: Gender, consumption and translation", Childhood, Vol. 12 No. 2, pp.221-237.

Sen, Saker, Zeynep Gurhan-Canli and Vicky Morwitz (2001), "Witholding Consumption: A Social Dilemma Perspective on Consumer Boycotts", Journal of Consumer Research, Vol.28 No.3, pp.399-417.

Spiggle, S. (1994), "Analysis and Interpretation of Qualitative Data in Consumer Research", Journal of Consumer Research, Vol. 21 No.3, pp.491-503.

Thompson, C.J. and Hirschman, E. (1995), "Understanding the Socialized Body: A Poststructuralist Analysis of Consumers' Self-Conceptions, Body Images and SelfCare Practices", Journal of Consumer Research, Vol. 22 No.2, pp.319-153.

Tinson J. and Nuttall P. (2010), "Exploring Appropriation of Global Cultural Rituals", Journal of Marketing Management, Vol.26, No.11/12, pp. 1074-1090

Wasserman, S. and Faust, K. (1994), Social Network Analysis: Methods and Applications, Cambridge University Press, New York, NY.

Weber, M. (1948), "Politics as a vocation", in Gerth, H. and Mills, C. (Eds), From Max Weber, Routledge, London, UK. 